\title{
Hydraulic Coupling Triaxial Test of Sandstone under Cyclic Loading Action
}

\author{
Xianqi Zhou ${ }^{1, *}$, Dengqi Guo ${ }^{1}$, Jin Yu ${ }^{2, *}$, Xin Zhang ${ }^{2}$ and Peijuan $\mathrm{Cao}^{3}$ \\ ${ }^{1}$ Xiamen University of Technology, Xiamen 361024, China \\ ${ }^{2}$ Fujian Research Center for Tunnelling and Urban Underground Space Engineering, Huaqiao Univ., Xiamen 361021, China \\ ${ }^{3}$ University of Florida, Gainesville, FL 32611, USA
}

Received 6 January 2021; Accepted 11 June 2021

\begin{abstract}
In deep underground engineering, surrounding rocks are subjected to cyclic loading and become prone to fractures due to the seepage pressure. To explore the mechanical properties, damage evolution, and permeability response characteristics of sandstone under cyclic loading action, three tests, namely, monotonic loading hydraulic coupling, constant amplitude and variable amplitude cyclic loading and unloading tests, were performed in this work. The mechanical characteristics, damage evolution, and permeability response characteristics of sandstone were then analyzed. Results show that, 1) under the monotonic loading hydraulic coupling action, the elasticity modulus of sandstone increases along with the confining pressure and decreases along with an increasing osmotic pressure, whereas the change in its strength is positively correlated to the elasticity modulus; 2) Given the limited compressible volume of broken sandstone, its permeability significantly decreases along with increasing confining pressure. Given that the permeable channels are changed along with the crack development laws under cyclic loading, the permeability change of sandstone after the yield stage differs from that under the conventional loading action, and the failure mode is classified as tensile-shear mixed failure; 3) A damage variable model of cyclic disturbance under cyclic loading-hydraulic coupling action was established. The conclusions obtained in the study provide references for deep underground engineering construction.
\end{abstract}

Keywords: sandstone, permeability, cyclic loading and unloading, hydraulic coupling, damage model

\section{Introduction}

With their large number of micropores and joint fissures, rock mass provides both a storage space and seepage channel for groundwater resources; however, they also introduce difficulties in engineering construction $[1,2]$. In deep underground excavation engineering under high stress and osmotic pressure, apart from the additional stress generated by stress adjustment after excavation, the deep surrounding rocks are also subjected to cyclic loading, such as blasting, mechanical rock drilling, and vehicle load, in the subsequent excavation construction. Under the complex load-hydraulic coupling action, new microfractures are formed from the original joints and fractures in natural rock mass, and these microfractures continuously propagate and run through one another before leading to rock failure [3].

Permeability is an index used to measure the ability of reservoirs to transport hydrocarbons and is recognized as one of the most important parameters in reservoir studies [4, 5]. The most essential coupling factor is the interaction between water seepage and rock deformation. Under hydraulic disturbance, an aggravated deformation, damage, failure, and instability will all take place when the environmental limit of a rock material is exceeded [6,7]. Given the complex environment of deep underground rock mass, the initial microscopic crevices inside them are highly prone to propagation and evolution due to high stress and osmotic pressure, thereby changing the macroscopic mechanical behavior and fracture modes of rock mass,

*E-mail address: xianqizhou@163.com; bugyu0717@163.com

ISSN: 1791-2377 @ 2021 School of Science, IHU. All rights reserved. doi:10.25103/jestr.143.25 substantially reducing their bearing capacity, and significantly increasing their deformation and permeability $[8,9]$.

To address these problems, researchers have explored the pore and fracture distribution in sandstone and the effects of confining and pore pressures on sandstone permeability [10-13], but a hydraulic coupling triaxial test of sandstone under cyclic loading action has been rarely conducted. Given the nonnegligible influence of cyclic loading on rock permeability, performing a hydraulic coupling triaxial test of sandstone under cyclic loading action is critical.

To this end, this study analyzes three schemes, namely, monotonic loading hydraulic coupling, constant amplitude, and variable amplitude cyclic loading-hydraulic coupling, by performing a hydraulic coupling triaxial test of sandstone under cyclic loading action. Afterward, a cyclic disturbance damage variable model under cyclic loading hydraulic coupling action is established to formulate the damage factor of rock specimens after the cyclic loading hydraulic coupling action from various angles, including deformation law, loading mode, hysteretic characteristics of permeability, and damage characteristics after cyclic disturbance. During the cyclic loading and unloading process, the residual strain of rock continuously increases, and the resulting damage continues to accumulate. The rock is not only subjected to the damage caused by osmotic pressure but also to the cyclic disturbance and damage brought by cyclic loading and unloading. The hydraulic coupling permeability characteristics of sandstone under the cyclic loading action are also explored to provide data support for a subsequent deep study of sandstone permeability characteristics and to 
provide references for deep underground engineering construction.

\section{State of the art}

Previous studies have investigated the permeability characteristics of sandstone under different conditions using various methods. Experimental results mainly focus on uniaxial and triaxial compression conditions. For instance, Liu X Z et al. [14] conducted uniaxial compression and permeability tests of homogenous and heterogenous singlefracture rocks to understand the seepage characteristics on the fracture surface of different rock strata yet ignored the triaxial hydraulic coupling characteristics. Yu J et al. [15] used a servo-controlled triaxial test system to experimentally study the permeability evolution laws in the whole stressstrain process under different confining and osmotic pressures, but their experiments were not carried out under cyclic loading action. To further understand the complex coupling between circulating fluids and the development of crack and damage, I. Faoro et al. [16] performed a flowthrough test on Etna basalt and Xifeng granite specimens and found that both permeability and reservoir evolve along with the damage in fracture density. Takashi Fujii et al. [17] studied the changes in the permeability of three soft rock types and found that permeability increases by one to three orders of magnitude during the fracturing process depending on the rock type. To understand the relationships of permeability and characteristic stress with the confining and pore pressures in the deformation process, Zhang L M et al. [18] performed a triaxial mechanical test of sandstone under hydraulic coupling action and different confining and osmotic pressures yet ignored the influence of cyclic loading. Many scholars have also probed the influence mechanism of rock permeability characteristics using theoretical models. For instance, Faruk Civan [19] proposed an effective theory and constitutive equation that accurately measures capillary pressure and relative permeability with or without considering the saturated impact. Sakhaee-Pour A and Agrawal Abhishek [20] analyzed the permeability of sandstone based on acoustic emission events and constructed a physical representation model of core pore space based on the hypothesis that pore throats have a random spatial distribution. However, this hypothesis was not supported by any evidence, hence making the model inapplicable. To study the split failure of fractured rock mass under seepagestress coupling action, Nie T Y [21] built a split evolution model based on curve propagation path under seepage-stress coupling action. Li $\mathrm{T}$ et al. [22] used the multi-relaxation time lattice Boltzmann method to simulate fluid seepage and to study the influence mechanism of microfracture networks on rock permeability.

Apart from experimental studies, numerical simulations have also been conducted in previous studies, with the related results being recognized in academic circles. Minoru Sato et al. [23] explored the influence of pore structure on the anisotropy of rock permeability and diffusion coefficient by combining an experiment with a numerical simulation. To understand the compressive and permeation behaviors of sandstone with weak anisotropy, Jin Y et al. [24] studied sandstones with weak anisotropy by conducting a triaxial compression test and using the 2D discrete element method and found that permeability increases much faster in specimen failures with a large stratification angle compared with the other directions. McBeck Jessica et al. [25] revealed the influence of crack development on rock failure in sandstone specimens with different porosities by using a discrete element model (DEM) and argued that the amplitude and rate of crack development increase toward the failure direction. By performing a seepage test of prefabricated jointed rocks under triaxial compressive stress, Lin C et al. [26] obtained the microcrack development laws under different prefabricated joint angles and used the particle flow code (PFC) to explain the energy dissipation and conversion laws of rocks from the meso-angle. Barroso Josue et al. [27] established a new two-scale computational model to describe the steady-state hydro-mechanical coupling in jointed rocks.

However, while the above studies mainly focus on the mechanical and permeability characteristics of sandstone, the permeability characteristics under cyclic loadinghydraulic coupling action have been ignored. To fill such gap, this study performs three tests to understand the mechanical properties, damage evolution, and permeability response characteristics of sandstone under a complex stress path. Afterward, a cyclic disturbance damage model under the cyclic loading-hydraulic coupling action is established to highlight the permeability characteristics of sandstone under different stress paths and to provide data support for subsequent in-depth studies on sandstone seepage characteristics.

The rest of this study is organized as follows. Section 3 describes the sandstone specimens, testing equipment, and test schemes employed in this study. Section 4 analyzes the mechanical response and permeability characteristics of sandstone based on the results of the three schemes, highlights the changes in sandstone permeability under different confining and osmotic pressures, and develops a cyclic disturbance damage variable model after the cyclic loading-hydraulic coupling test of sandstone. Section 5 summarizes the paper and presents the conclusions.

\section{Methodology}

\subsection{Rock specimens and testing equipment}

The specimens are prepared through core drilling, cutting, grinding, rinsing, and air drying. Feldspathic sandstone was collected from the tunnel surrounding rocks in Xuancheng, Anhui Province. This experimental sandstone had a red color and a density of approximately $2.40 \mathrm{~g} \cdot \mathrm{cm}^{-3}$. The collected specimens were processed into a $\Phi 50 \mathrm{~mm} \times \mathrm{H} 100$ mm cylinder with a flat disc and a $90^{\circ}$ angle with the central axis. The triaxial pressure servo test system codeveloped by Huaqiao University and Changchun Keyi Instruments was used as the testing equipment. The rock specimen and equipment are shown in Fig. 1. A total of 30 specimens were prepared, of which 3 were randomly chosen for the conventional triaxial compression test. The basic mechanical parameters of all specimens were then obtained. The triaxial compressive strength, elasticity modulus, and Poisson' $\mathrm{s}$ ratio of these three specimens were $118.96 \mathrm{MPa}$, $33.3 \mathrm{GPa}$, and 0.485 , respectively. Meanwhile, the other 27 rock specimens were divided into three groups, with each group containing nine specimens. Those specimens with wave velocity anomaly were excluded after screening with an ultrasonic equipment to eliminate the influence of rock discreteness as much as possible. 


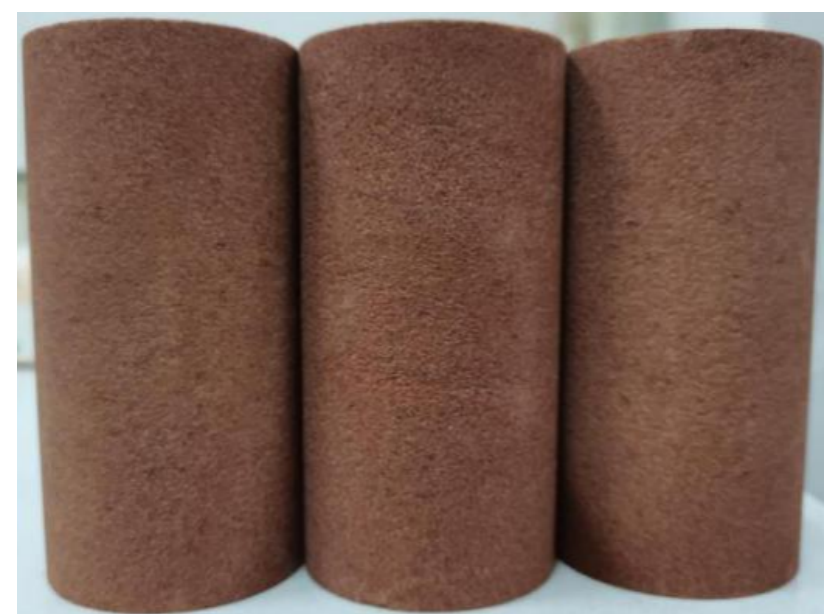

(a) Standard triaxial sandstone specimen

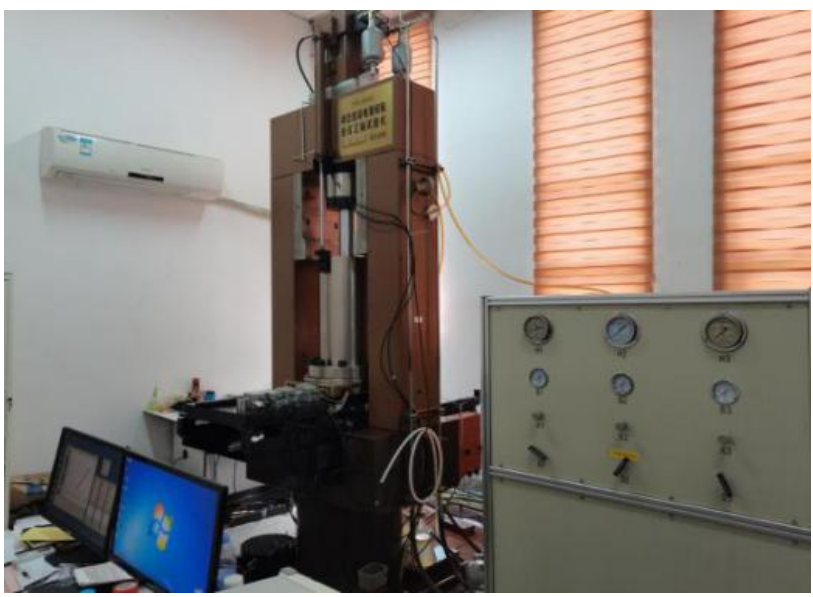

(b) Triaxial pressure servo system of rocks

Fig. 1. Sandstone Specimens and Testing Equipment

\subsection{Test schemes}

A permeability test was performed using the transient-flow method, and the seepage is illustrated in Fig. 2. The rock specimens and equipment used were identical in all test schemes, and a vacuum saturation of rock specimens was conducted before the test. The rock specimens were soaked in water before the formal test to prevent air from entering these specimens and interfering with the test.

Scheme 1 (Monotonic loading-hydraulic coupling test)

Step 1) The specimen was installed. After coming in contact with the pressure head, the specimen was loaded to the target confining pressure by means of stress control, and the confining pressure was kept unchanged throughout the test.

Step 2) Osmotic pressure was applied and elevated to the target value at a rate of $1 \mathrm{MPa} / \mathrm{min}$. The pressure was kept unchanged to ensure that the water permeates into the pores of sandstone.

Step 3) Deviatoric stress was applied at a loading rate of $0.05 \mathrm{MPa} / \mathrm{s}$ until the specimen reached failure.

Step 4) The confining and osmotic pressures were changed, the hydraulic coupling test was performed in a similar way. Parameters such as curve and time were recorded, and the permeability values of rock specimen across seven stages were determined.
Scheme 2 (Constant amplitude cyclic loading-hydraulic coupling test)

Step 1) The same steps 1) and 2) in scheme 1 were applied.

Step 2) Deviatoric stress was loaded to $67 \%$ of triaxial strength at a rate of $0.05 \mathrm{MPa} / \mathrm{s}$ using the stress control method. Specifically, after reaching $80 \mathrm{MPa}$, cyclic loading and unloading were performed using the same control method at the same rate, and permeability was measured by selecting four points, namely, 20, 40, 60, and $80 \mathrm{MPa}$, in each loading and unloading process.

Step 3) The confining and osmotic pressures were changed, a hydraulic coupling test was performed under cyclic loading in a similar way, and parameters such as curve, permeability, and time were recorded.

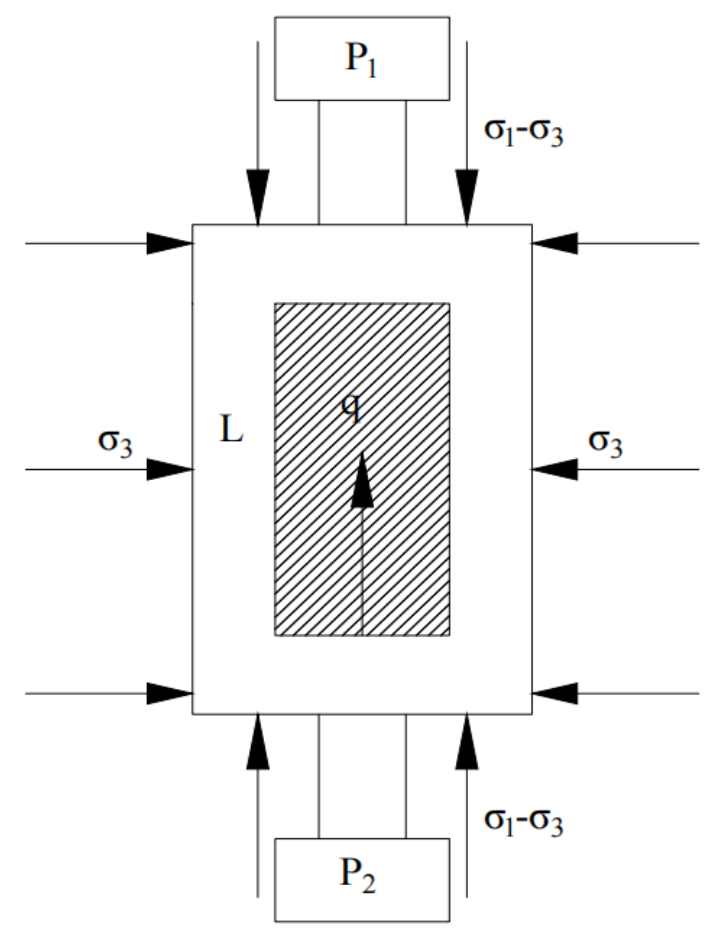

Fig. 2. Schematic Diagram of Seepage under the Transient Flow Method

Scheme 3 (Variable amplitude cyclic loading-hydraulic coupling test)

Step 1) The same steps 1) and 2) in scheme 1 were applied.

Step 2) Axial load was applied using the stress control method at a rate of $0.05 \mathrm{MPa} / \mathrm{s}$, the cyclic loading and unloading test was repeated 5 times, and 5 measuring points were arranged to determine the permeability in the initial, post-cycling, and post-peak stages.

Step 3) The confining and osmotic pressures were changed, the cyclic loading and unloading coupling test was repeated 5 times using the same method under different amplitudes, the curve was recorded, and parameters such as stress-strain and time were acquired

Table 1 lists the test schemes in detail.

Table 1. Test Schemes

\begin{tabular}{l|l|l|l|l|l|l|l|l|l} 
Schemes & numbered & $\begin{array}{l}\text { confining } \\
\text { pressure }\end{array}$ & $\begin{array}{l}\text { osmotic } \\
\text { pressure }\end{array}$ & numbered & $\begin{array}{l}\text { confining } \\
\text { pressure }\end{array}$ & $\begin{array}{l}\text { osmotic } \\
\text { pressure }\end{array}$ & $\begin{array}{l}\text { numbered } \\
\text { pressure }\end{array}$ & $\begin{array}{l}\text { osmotic } \\
\text { pressure }\end{array}$ \\
\hline Scheme 1 & $\mathrm{~A} 10-1$ & $10 \mathrm{MPa}$ & $1 \mathrm{MPa}$ & $\mathrm{A} 15-1$ & $15 \mathrm{MPa}$ & $1 \mathrm{MPa}$ & $\mathrm{A} 20-1$ & $20 \mathrm{MPa}$ & $1 \mathrm{MPa}$
\end{tabular}




\begin{tabular}{|c|c|c|c|c|c|c|c|c|c|}
\hline & $\begin{array}{l}\text { A } 10-5 \\
\text { A } 10-9\end{array}$ & & $\begin{array}{l}5 \mathrm{MPa} \\
9 \mathrm{MPa}\end{array}$ & $\begin{array}{l}\text { A } 15-5 \\
\text { A } 15-9\end{array}$ & & $\begin{array}{l}5 \mathrm{MPa} \\
9 \mathrm{MPa}\end{array}$ & $\begin{array}{l}\text { A20-5 } \\
\text { A20-9 }\end{array}$ & & $\begin{array}{l}5 \mathrm{MPa} \\
9 \mathrm{MPa}\end{array}$ \\
\hline Scheme 2 & $\begin{array}{l}\text { B10-1 } \\
\text { B10-5 } \\
\text { B10-9 }\end{array}$ & $10 \mathrm{MPa}$ & $\begin{array}{l}1 \mathrm{MPa} \\
5 \mathrm{MPa} \\
9 \mathrm{MPa}\end{array}$ & $\begin{array}{l}\text { B15-1 } \\
\text { B15-5 } \\
\text { B15-9 }\end{array}$ & $15 \mathrm{MPa}$ & $\begin{array}{l}1 \mathrm{MPa} \\
5 \mathrm{MPa} \\
9 \mathrm{MPa}\end{array}$ & $\begin{array}{l}\text { B20-1 } \\
\text { B20-5 } \\
\text { B20-9 }\end{array}$ & $20 \mathrm{MPa}$ & $\begin{array}{l}1 \mathrm{MPa} \\
5 \mathrm{MPa} \\
9 \mathrm{MPa}\end{array}$ \\
\hline Scheme 3 & $\begin{array}{l}\text { C10-1 } \\
\text { C10-5 } \\
\text { C10-9 }\end{array}$ & $10 \mathrm{MPa}$ & $\begin{array}{l}1 \mathrm{MPa} \\
5 \mathrm{MPa} \\
9 \mathrm{MPa}\end{array}$ & $\begin{array}{l}\text { C15-1 } \\
\text { C15-5 } \\
\text { C15-9 }\end{array}$ & $15 \mathrm{MPa}$ & $\begin{array}{l}1 \mathrm{MPa} \\
5 \mathrm{MPa} \\
9 \mathrm{MPa}\end{array}$ & $\begin{array}{l}\mathrm{C} 20-1 \\
\mathrm{C} 20-5 \\
\mathrm{C} 20-9\end{array}$ & $20 \mathrm{MPa}$ & $\begin{array}{l}1 \mathrm{MPa} \\
5 \mathrm{MPa} \\
9 \mathrm{MPa}\end{array}$ \\
\hline
\end{tabular}

\section{Result Analysis and Discussion}

\subsection{Monotonic loading-hydraulic coupling test results and analysis}

\subsubsection{Strength and failure characteristic analysis}

The failure modes of the rock specimens (all shear failure) are shown in Fig. 3. The failure characteristics (i.e., shear slip failure) of these specimens are similar under the monotonic hydraulic coupling test, the crack propagation direction is largely parallel to or has a very small included angle with the loading direction, the main crack plays a dominant role, only few secondary cracks are present, and the cracks are mutually crossed. The failure mode of these specimens does not radically change during the failure process. Specifically, the cracks are initiated and propagated before leading to shear failure in the form of several main cracks, and the failure rate is high.

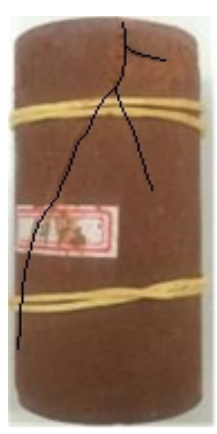

(a)

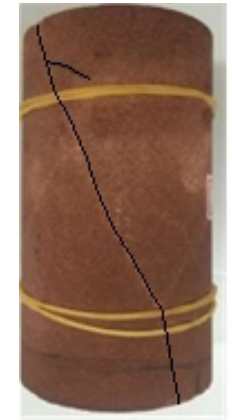

(b)

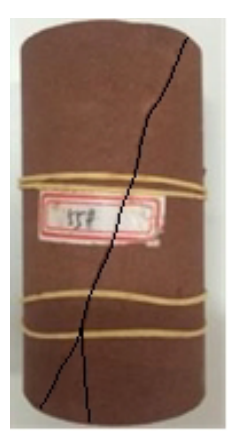

(c)
Fig. 3. Rock Failure Modes in the Monotonic Hydraulic Coupling Test under a Confining Pressure of $10 \mathrm{MPa}$ (The Osmotic Pressures of (a), (b), and (c) Are Kept at 1, 5, and 9MPa, Respectively).

Using the data acquired through the monotonic loadinghydraulic coupling test, the relation curves of sandstone stress and permeability with strain are drawn as shown in Fig. 4. Compared with conventional loading, the failure degree of the rock specimens is more serious during the whole rock failure process under the monotonic loadinghydraulic coupling test. The stress-strain curve under an osmotic pressure of $1 \mathrm{MPa}$ is taken as an example, and the peak strength of sandstone significantly decreases along with an increasing osmotic pressure. At the initial loading stage, the rock specimens are subjected to the coupling effect of confining and osmotic pressures, the micropores inside these rocks are compacted, the microcracks are gradually sealed, the deformation characteristics of these specimens show linear relations, and their permeability gradually declines. At the elastic deformation stage, as the elasticity modulus of the rock specimens is kept almost unchanged, the cracks develop stably, the original seepage channel is compacted, and the permeability of these rocks slightly changes. At the yield stage, the new cracks formed at the previous stage gradually propagate, and the resulting damage accumulates through cracks, hence creating a seepage channel for the fluid and increasing the permeability of the specimens. At the later stage of peak stress, the permeability of the sandstone specimens is reduced and even unchanged with the continuous application of stress because after these rocks enter the plastic deformation stage, some small particles block the previously formed cracks due to the relative slippage of the rock fracture surface, and the permeability tends to be stable and even reduces.

Under a constant osmotic pressure, the peak strength of the specimens is positively correlated with the confining pressure. When the confining pressure is constant, the osmotic pressure is negatively correlated with peak stress. The essence of rock failure is crack propagation until a macroscopic fracture plane is formed. Under a low osmotic pressure, the elasticity modulus before the peak stress of sandstone increases along with confining pressure. As the pores are compacted by the confining pressure, the seepage rate of fluid into the pore channel of rocks is reduced, and the rock breakage characteristics become more obvious along with increasing osmotic pressure. Before the leptokurtic point, the curve slope slowly reduces. Under the influence of osmotic pressure, water rapidly seeps into the natural pores and fractures of the rock specimens, thereby reducing the effective confining pressure and leading to an inverse relation between the peak stress of sandstone and its osmotic pressure.

\subsubsection{Permeability characteristics analysis}

The permeability of the sandstone specimens is shown in Fig. 4. Under an osmotic pressure of $1 \mathrm{MPa}$ and confining pressures of 10,15 , and $20 \mathrm{MPa}$, the permeabilities at the post-peak stage are $12.27 \times 10^{-15} \mathrm{~m}^{2}, 9.98 \times 10^{-15} \mathrm{~m}^{2}$, and $9.01 \times 10^{-15} \mathrm{~m}^{2}$, respectively. Under the same osmotic pressure, a higher confining pressure corresponds to a lower permeability at the same stage. When stress is continuously applied, the specimens experience a shear failure, and the capillary cracks inside the specimen gradually develop and evolve into fractures, thereby increasing permeability. At the later stage of peak stress, the permeability of the specimens is reduced and even unchanged along with the application of stress because after these rocks enter the plastic deformation stage, they undergo a comprehensive failure as the stress continues to increase. Some small particles block the previously formed cracks owing to the relative slippage of the fracture surface, and the permeability of the specimens becomes stable and even reduces [28].

In sum, under a constant confining pressure, a greater osmotic pressure corresponds to a higher permeability at the same stage. With the progression of rock failure, the permeability gap of the rock specimens increases under different osmotic pressures. After these rocks reach their peak strength, their permeability becomes stable and even reduces. However, when these rocks enter a complete failure stage, their permeability is obviously increased. 


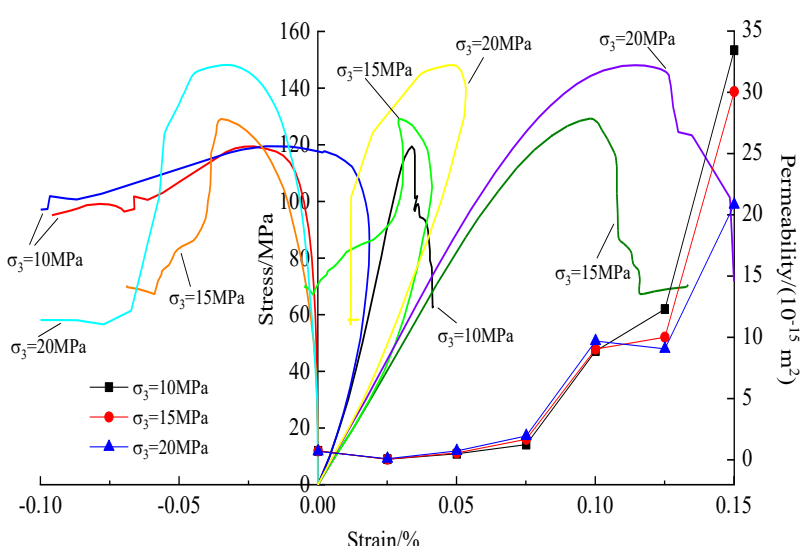

(a) $P_{g}=1 \mathrm{MPa}$

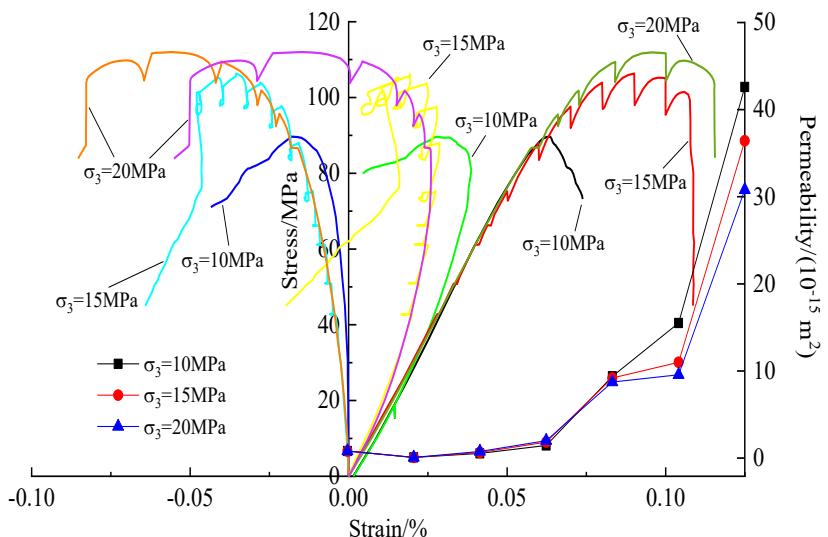

(b) $P_{g}=5 \mathrm{MPa}$

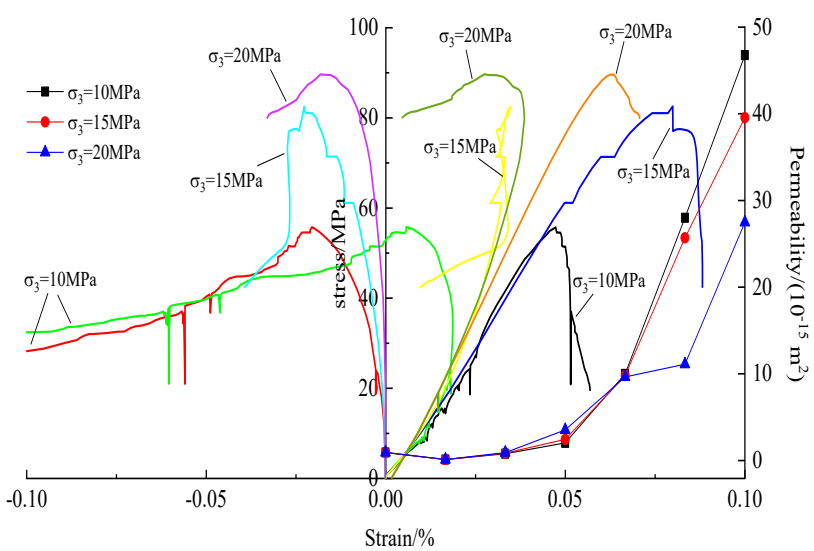

(c) $P_{g}=9 \mathrm{MPa}$

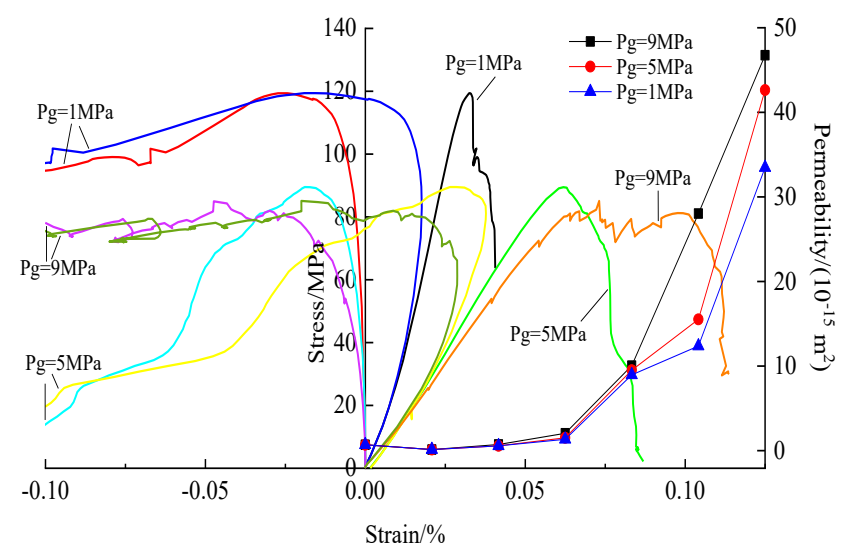

(d) $\sigma_{3}=10 \mathrm{MPa}$

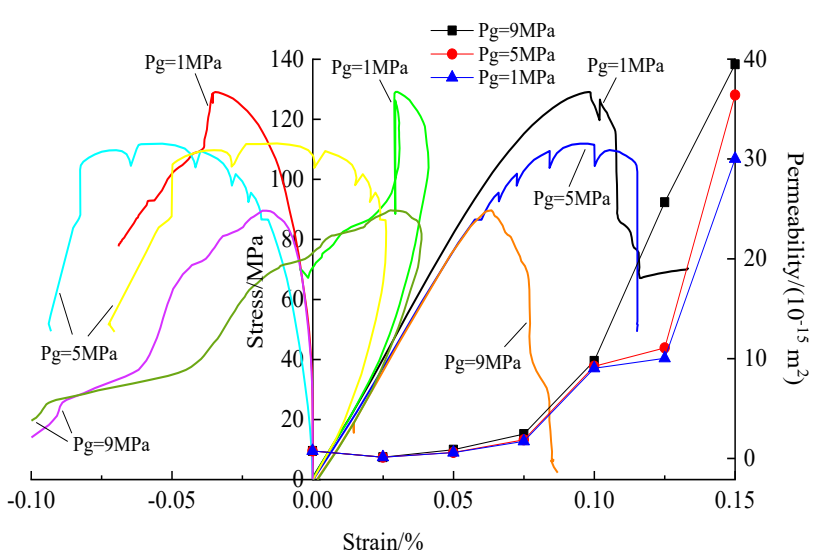

(e) $\sigma_{3}=15 \mathrm{MPa}$

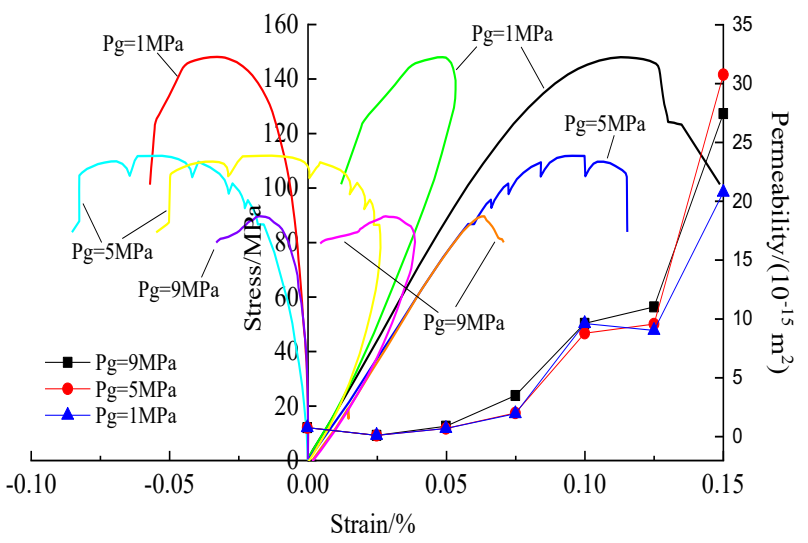

(f) $\sigma_{3}=20 \mathrm{MPa}$

Fig. 4. Relation Curves of Sandstone Stress and Permeability with Strain ( $P_{g}$ Is the Osmotic Pressure, and $\sigma_{3}$ Is the Confining Pressure).

\subsection{Results of five constant amplitude cyclic loading- hydraulic coupling tests and analysis}

\subsubsection{Strength and failure characteristic analysis}

The stress-strain curves of sandstone under the confining pressure of $10 \mathrm{MPa}$ and different osmotic pressures are shown in Fig. 5.

Both peak strength and elasticity modulus of rock are smaller under an osmotic pressure of $1 \mathrm{MPa}$ relative to the monotonic hydraulic coupling test because under such pressure, accumulative rock damage is generated due to cyclic loading, thereby accelerating the development of the original fracture in the rock and reducing its peak stress. As the stress continues to increase, the fractures penetrate the rock until reaching failure.

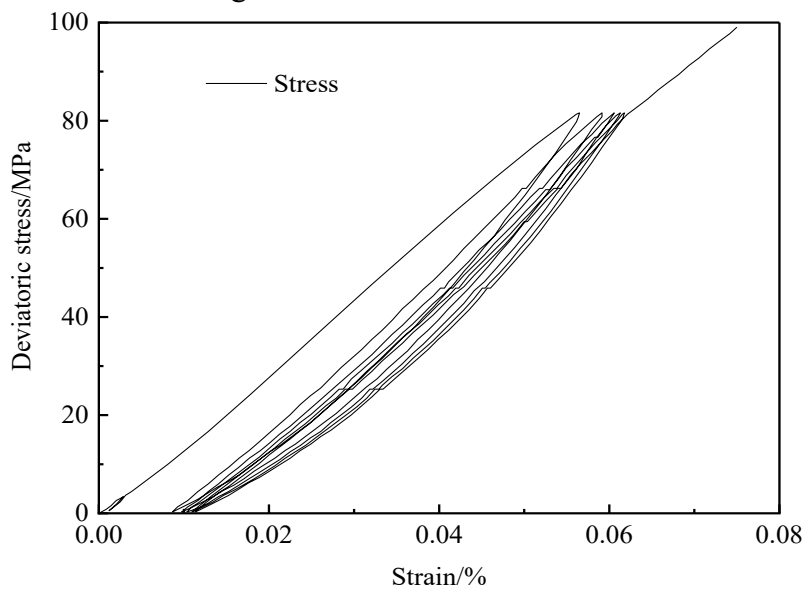

(a) $P_{g}=1 \mathrm{MPa}$ 


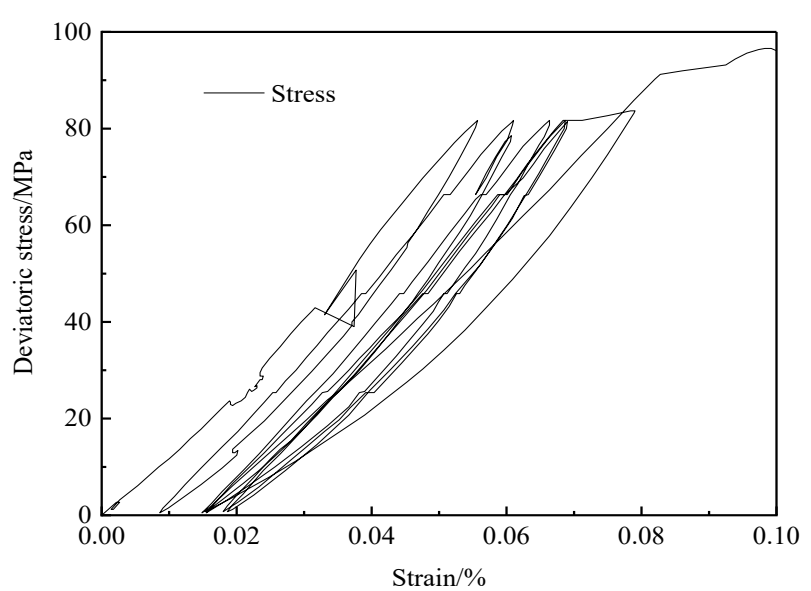

(b) $P_{g}=5 \mathrm{MPa}$

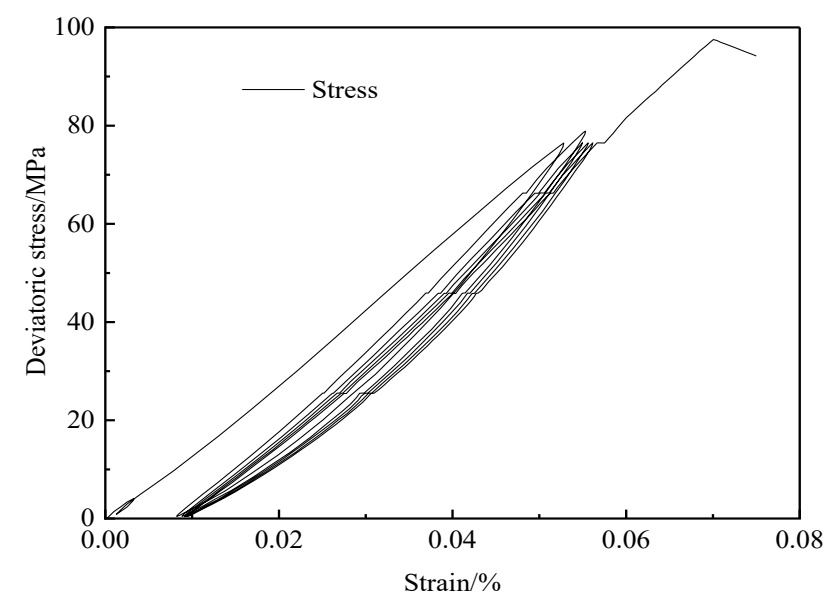

(c) $P_{g}=9 \mathrm{MPa}$

Fig. 5. Stress-Strain Curves of Five Constant Amplitude Cyclic Loading-Hydraulic Coupling Tests under a Confining Pressure of 10 $\mathrm{MPa}$

Such phenomenon can be explained by the different internal tectonic mechanisms of rocks. At the initial loading stage, the cracks in the rock are basically original pores and cracks in natural rock. As the stress increases, the internal initial cracks continue to expand, and new fractures are formed. At the loading stage, these cracks are sealed, the permeability of the sandstone is reduced, and its peak strength is enhanced by virtue of its elastic recoverability.

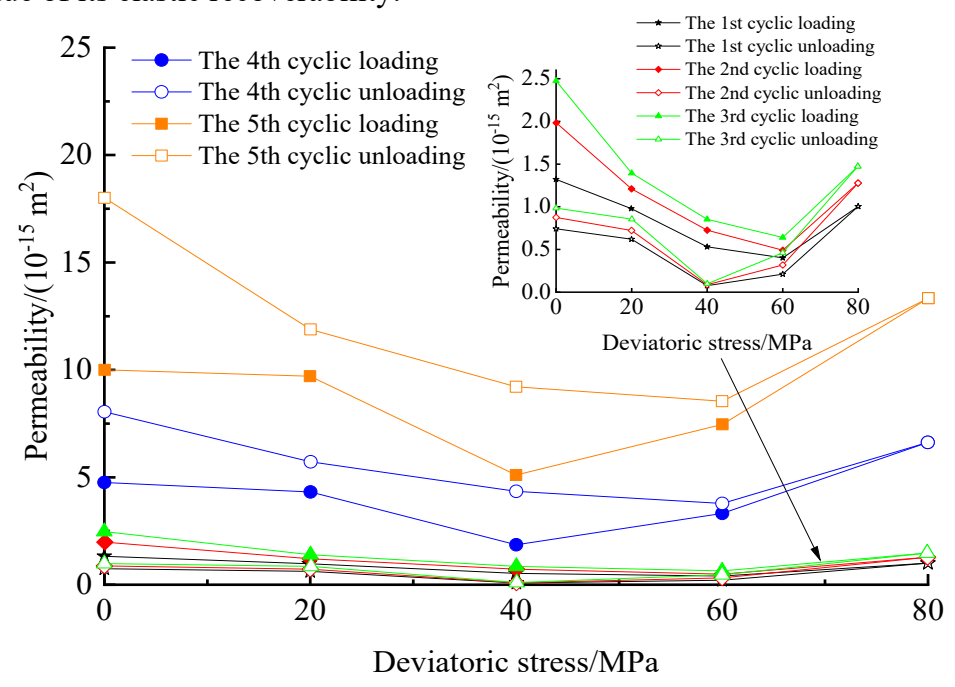

(a) $\sigma_{3}=10 \mathrm{MPa}$

\subsubsection{Permeability characteristics analysis}

As shown in Fig. 6, the sandstone permeability in the loading process is unequal to that in the unloading process under the same deviatoric stress. In each loading and unloading cycle, the permeability in the former process is smaller than that in the latter. For example, during the third loading and unloading cycle under a confining pressure of $10 \mathrm{MPa}$, the sandstone permeability at the deviatoric stress of $60 \mathrm{MPa}$ in the loading process is $64.01 \times 10^{-17} \mathrm{~m}^{2}$ whereas that in the unloading process is $46.19 \times 10^{-17} \mathrm{~m}^{2}$. In each loading and unloading process, the rock permeability changes under various confining pressures as the deviatoric stress increases, where permeability fluctuates greatly under medium and low confining pressures of $10 \mathrm{MPa}$ and $15 \mathrm{MPa}$. The rock has a low compaction value, and after the compaction stage, fractures start to form, and the rock permeability starts to increase. At the loading stage, the permeability of the rock initially decreases and then increases along with deviatoric stress. At the unloading stage, the sandstone permeability gradually increases along with decreasing deviatoric stress. At the compaction stage with a high confining pressure, no fractures are formed on the rock, whereas its permeability decreases yet increases as fractures start to form.

The permeability of the rock increases after the cyclic loading and unloading process. After the third cycle, such permeability significantly increases, with the increase under medium and low confining pressures being more obvious that that under high confining pressure. Under a confining pressure of $20 \mathrm{MPa}$, the increase amplitude of rock permeability is reduced. As the cycle index increases, the internal structure of sandstone becomes more compact and fractures gradually develop due to the cyclic hardening effect under cyclic loading. However, cyclic loading brings irreversible fatigue damage to the rock, destroys its internal structural stability, and forms many fractures of different sizes and shapes. The size and shape of these fractures are the primary factors that influence rock permeability. 


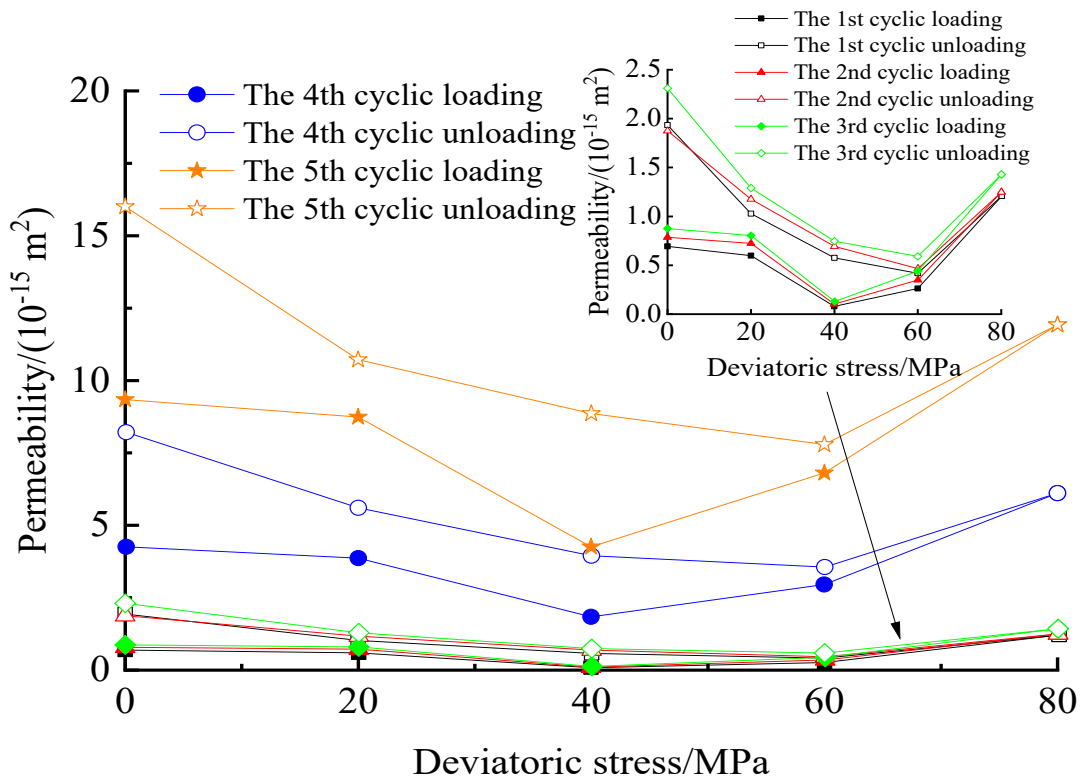

(b) $\sigma_{3}=15 \mathrm{MPa}$

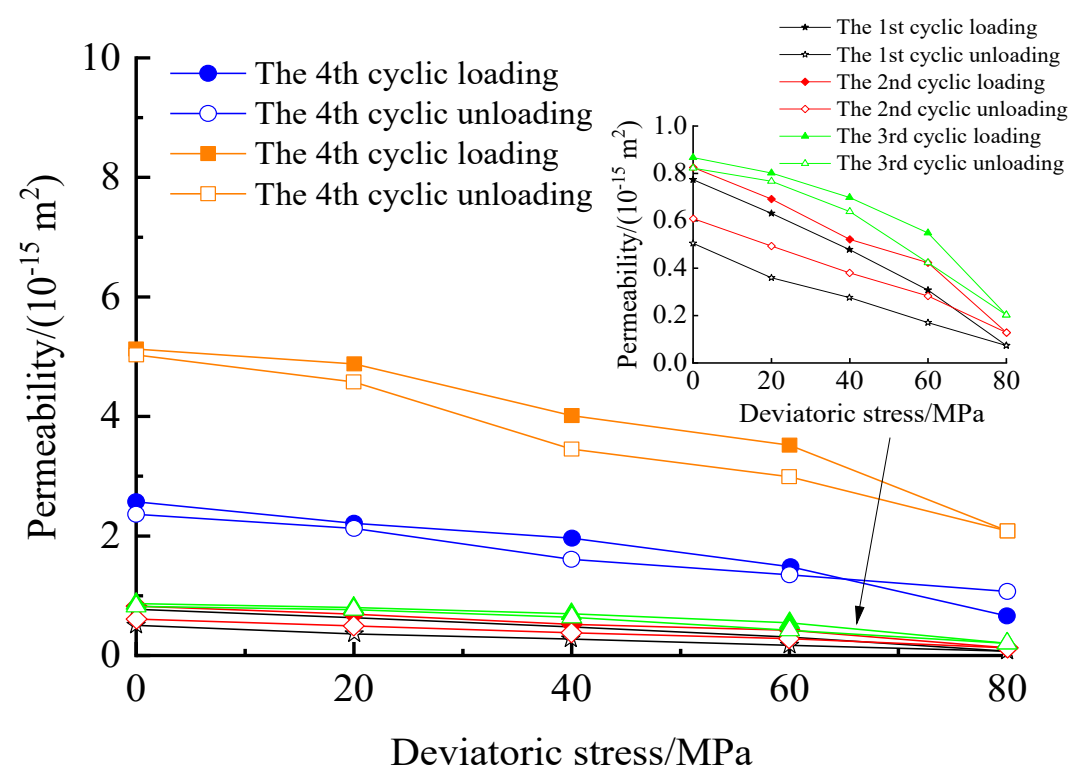

(c) $\sigma_{3}=20 \mathrm{MPa}$

Fig. 6. Permeability Change Curves after Five Constant Amplitude Cyclic Loading and Unloading Cycles under an Osmotic Pressure of $1 \mathrm{MPa}$

\subsection{Results of five variable amplitude cyclic loading- hydraulic coupling tests and analysis}

\subsubsection{Strength and failure characteristics analysis}

Given that the stress-strain curves under different confining pressures are consistent in the variable amplitude cyclic loading-hydraulic coupling tests of sandstone, only the relation curves under the confining pressure of $20 \mathrm{MPa}$ are shown in Fig. 7.

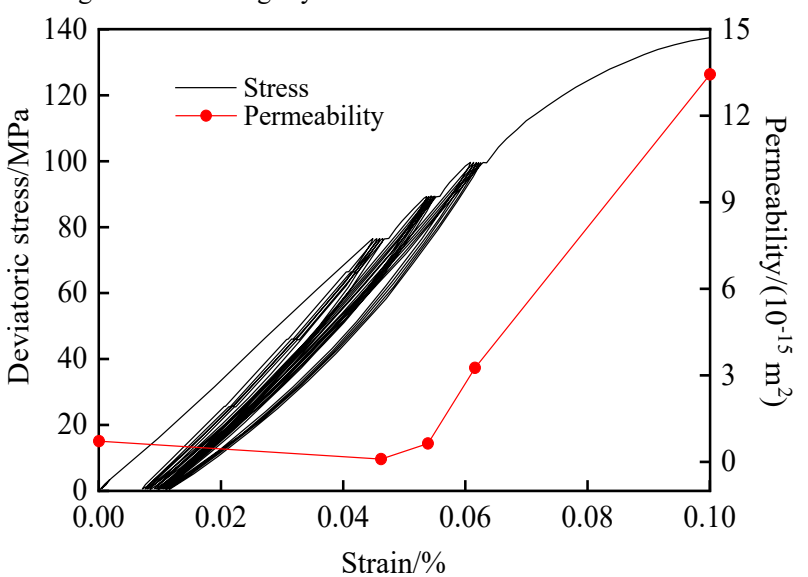

(a) $P_{g}=1 \mathrm{MPa}$ 


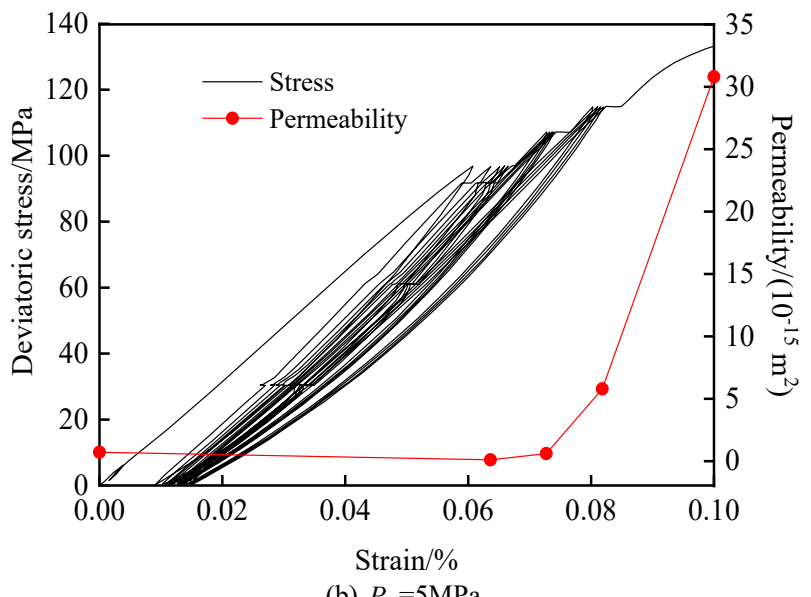

(b) $P_{g}=5 \mathrm{MPa}$

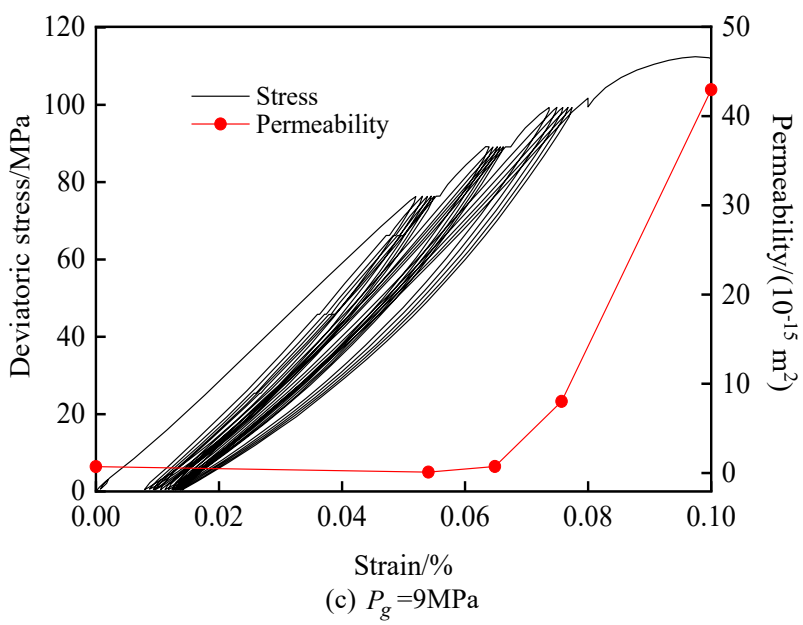

Fig. 7. Relation Curves of Sandstone Stress and Permeability with Strain under a Confining Pressure of $20 \mathrm{MPa}$.

Under variable amplitude cyclic loading action, the peak stress of sandstone under the same confining pressure is gradually reduced along with increasing osmotic pressure. Under the same osmotic pressure, the peak stress gradually increases along with confining pressure. At cycling point 1 , the rock strain significantly changes from the first to second cycles before reaching stability. In this process, the density of the hysteretic loops increases.

Compared with the cyclic loading and unloading and monotonic loading-hydraulic coupling test, the peak strength is obviously reduced after the cyclic loading and unloading. Before reaching peak stress, the elasticity modulus slightly increases along with confining pressure. Fig. 8 shows the post-failure specimen under a confining pressure of $10 \mathrm{MPa}$. Compared with sandstone under the variable amplitude cyclic loading-hydraulic coupling test and monotonic loading-hydraulic coupling test, the specimen crushing degree is higher, and many rock fragments fall off. The failure forms of the specimens are largely identical in the cyclic loading/unloading-hydraulic coupling tests, complex failure modes start to appear, the direction of stress application has a small included angle pointing toward the crack evolution direction, and the most serious crushing is observed in the middle of the specimen.

\subsubsection{Permeability characteristics analysis}

According to the relation curves shown in Figure 7, under the 5 variable amplitude cyclic loading and unloading tests, the sandstone permeability is directly proportional to osmotic pressure under a constant confining pressure and different osmotic pressures yet is inversely proportional to confining pressure under a constant osmotic pressure. The sandstone permeabilities in the peak stage under different osmotic pressures are $20.37 \times 10^{-15} \mathrm{~m}^{2}, 33.24 \times 10^{-15} \mathrm{~m}^{2}$, and $31.25 \times 10^{-15} \mathrm{~m}^{2}$, respectively. Under a constant osmotic pressure, the sandstone permeability is obviously reduced at cycling point 1 . The permeability increases most obviously when the failure stage gradually evolves especially from cycling point 3 to the peak stage. Under an osmotic pressure of $1 \mathrm{MPa}$, the sandstone permeability reduces from $20.37 \times$ $10^{-15} \mathrm{~m}^{2}$ to $13.42 \times 10^{-15} \mathrm{~m}^{2}$ in the peak stage as the confining pressure increases and changes along with increasing osmotic pressure. Under an osmotic pressure of 9 $\mathrm{MPa}$, fractures start to appear in the sandstone, and its permeability increases.

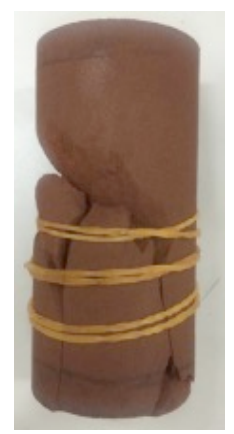

(a)

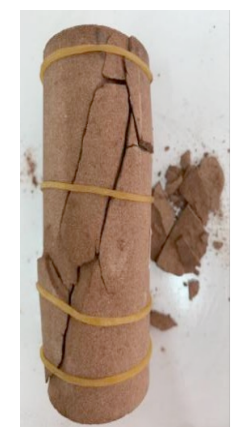

(b)

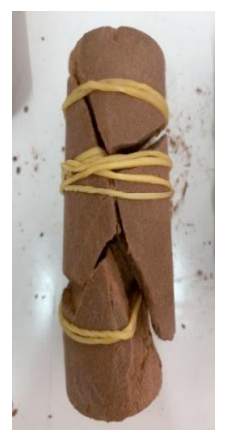

(c)
Fig. 8. Rock Failure Forms after Cyclic Loading-Hydraulic Coupling Tests under a Confining Pressure of $10 \mathrm{MPa}$ (The Confining Pressures of (a), (b), and (c) Are Held at 10, 15, and $20 \mathrm{MPa}$, Respectively).

The changes in sandstone permeability under cyclic loading action are different from those recorded in the conventional hydraulic coupling test with the osmotic pressure and confining pressure. To figure out their similarity, the rock is still under a relatively compact state in the initial loading stage, and the cyclic loading and unloading do not cause cyclic disturbance damage to the rock specimen. The situation in this case is the same as that under the conventional hydraulic coupling test, but only the loading modes are inconsistent, which results in inconsistent permeability values. The difference mainly appears after the dilatation stage, which is mainly related to the sandstone failure mode and crack development. Overall, the rock permeability under cyclic loading action is greater than that under monotonic loading action.

The rock has a high sliding friction rate under high osmotic pressure, leading to many rock fragments that cannot be unlinked from the permeation path. This phenomenon grows serious after failure and leads to a reduction in permeability. Under a low osmotic pressure, the internal cracks in the specimen slide slowly to form a dislocating fault plane, which generates more permeation paths. With the further evolution and development of cracks, only a small number of rock fines are formed, which fail to block the dislocating fault plane and new cracks. In other words, the permeability is high under a low osmotic pressure.

\subsection{Cyclic disturbance damage variable model after cyclic loading-hydraulic coupling tests}

\subsubsection{Derivation of cyclic disturbance damage variable model}


The model for expressing the damage of many materials in practical engineering is formulated as $[29,30]$

$$
D=\frac{\varepsilon_{r}-\varepsilon_{r 0}}{\varepsilon_{r c}-\varepsilon_{r 0}}
$$

Where $\varepsilon_{r}$ is the residual plastic strain of the rock specimen, $\varepsilon_{r 0}$ is the initial residual plastic strain, and $\varepsilon_{r c}$ is the cumulative residual plastic strain.

The above equation considers fatigue damage without secondary fatigue damage based on monotonic loading. However, in the step-by-step cyclic loading and unloading process, the rock is also subjected to the cyclic disturbance damage brought by this loading and unloading process. Therefore, the damage variable model studied by Li S C et al. [31] was improved in this study. The specific derivation process is as follows.

Assume that under the uniaxial condition, the constitutive equation of rock damage is

$$
1-D=\frac{\sigma \cdot F}{E \cdot \varepsilon}
$$

where $\mathrm{D}$ is the damage variable, $\mathrm{F}$ is the osmotic pressure, $\mathrm{E}$ is the elasticity modulus, $\sigma$ is the axial stress value, and $\varepsilon$ is the axial strain value.

In the derivation of the damage model, the change in the damage variable must sufficiently correspond to each loading and unloading process. This damage is assumed to be linearly correlated with the change in permeability. Therefore, the permeability value after completing the cycle should be considered, and the damage development in the rock fatigue loading process represents the specimen damage characteristics. $\sigma$ is set to a constant value by default. The derivatives of $\varepsilon$ are solved from both sides of the above equation and then simplified to obtain

$$
d D=\frac{\sigma \cdot F}{E \cdot \varepsilon^{2}} d \varepsilon
$$

The axial strain is assumed to be $\varepsilon_{0}$ in the first cycle, and no rock damage is assumed by default. After all cycles are ended, the axial strain is $\varepsilon_{d}$, the damage variable is 1 , and the integral is taken from the Eq. (3) to obtain

$$
\begin{aligned}
& \int_{0}^{D} d D=\frac{\sigma \cdot F}{E} \int_{\varepsilon_{0}}^{\varepsilon} \frac{1}{\varepsilon^{2}} d \varepsilon \\
& D=\frac{\sigma \cdot F}{E}\left(\frac{1}{\varepsilon_{0}}-\frac{1}{\varepsilon}\right)+C
\end{aligned}
$$

when $\mathrm{D}=0, \varepsilon_{d}=\varepsilon_{0}$ is substituted into the above equation to obtain $\mathrm{C}=0$. Under $\mathrm{D}=1$, the following can be obtained by substituting $\varepsilon=\varepsilon_{d}$ into the above equation:

$$
\frac{\sigma \cdot F}{E}=\frac{\varepsilon_{0} \cdot \varepsilon_{d}}{\varepsilon_{d}-\varepsilon_{0}}
$$

which yields

$$
D=\frac{\varepsilon_{d}\left(\varepsilon-\varepsilon_{0}\right)}{\varepsilon\left(\varepsilon_{d}-\varepsilon_{0}\right)}
$$

Under multiaxial cyclic loading and unloading, the cyclic stress-strain curves can usually be expressed in the exponential function form according to J Dean Morrow et al. [32]. Specifically, the constitutive relation of materials under cyclic loading action is

$$
\varepsilon=\varepsilon_{e}+\varepsilon_{p}=\frac{\varepsilon_{a}}{E}+\left(\frac{\sigma_{a}}{U}\right)^{\frac{1}{h}}
$$

where is the total strain, is the elastic strain, is the plastic strain, is the total stress, $U$ is the cyclic strength coefficient, and $\mathrm{h}$ is the cyclic strain hardening index. The following can be obtained through Lemaitre' $s$ strain equivalence hypothesis:

$$
\frac{\sigma \cdot F}{E}=\frac{\varepsilon_{0} \cdot \varepsilon_{d}}{\varepsilon_{d}-\varepsilon_{0}}
$$

Under triaxial cyclic loading and unloading, the following can be obtained according to Eqs. (8) and (9):

$$
|1-D|=\frac{E \cdot F \cdot \varepsilon_{1}}{\left(\varepsilon_{2}+\varepsilon_{3}-\sqrt[h]{\frac{\sigma_{a}}{U}}\right)}
$$

The above equation represents the derived damage variable model of rocks under the cyclic loading/unloadinghydraulic coupling test. By following clear logic with only few parameters, this formula is applicable to the definition of damage variable under the uniaxial and triaxial cyclic loading and unloading seepage tests.

\subsubsection{Parameter determination and calculation for the cyclic disturbance damage variable model}

The parameters are selected according to the definitions of related fatigue parameters under material fatigue tests given in Fatigue Performance Test Design and Data Processing compiled by Zhentong Gao [33].

As the cyclic loading and unloading tests under three different amplitudes are implemented in this study, different cyclic strength coefficients are acquired under various amplitudes [34, 35]. By taking the cyclic loading/unloadinghydraulic coupling test of rocks under osmotic pressures of $20 \mathrm{MPa}$ and $1 \mathrm{MPa}$ as an example, the fitted $\lg \varepsilon_{a}-\lg N_{f}$ relational graph is shown in Fig. 9(a), where $\varepsilon_{a}$ is the corresponding axial strain under each cyclic loading and unloading, and $N_{f}$ represents the number of cycles. The cyclic strength coefficient is defined as the slope of this fitted relation curve.

Under the aforementioned example, the cyclic strain hardening index is defined as the slope of the fitted $\lg \sigma_{a}-\varepsilon_{a}$ relation in Fig. 9(b), where is the stress value under the corresponding cyclic amplitude, and $\varepsilon_{a}$ is the corresponding axial strain in each cyclic loading and unloading process. 


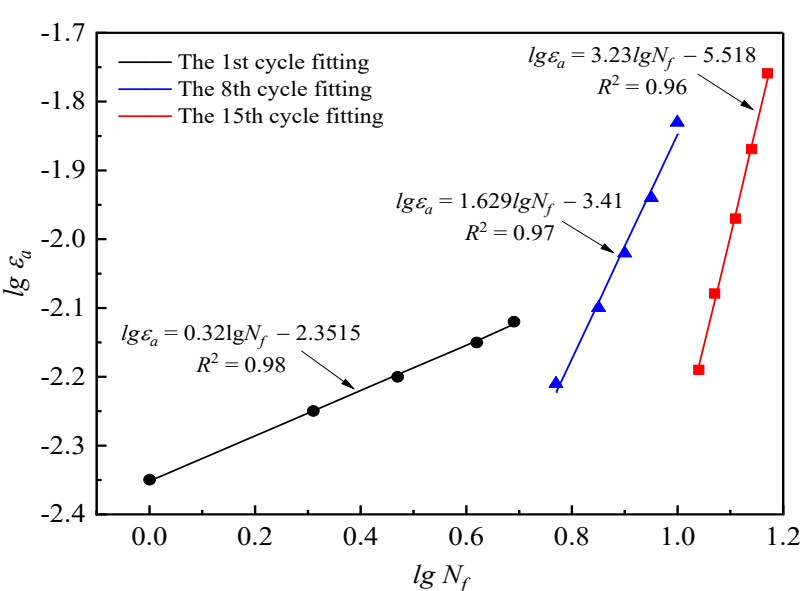

(a) $\lg \varepsilon_{a}-\lg N_{f}$

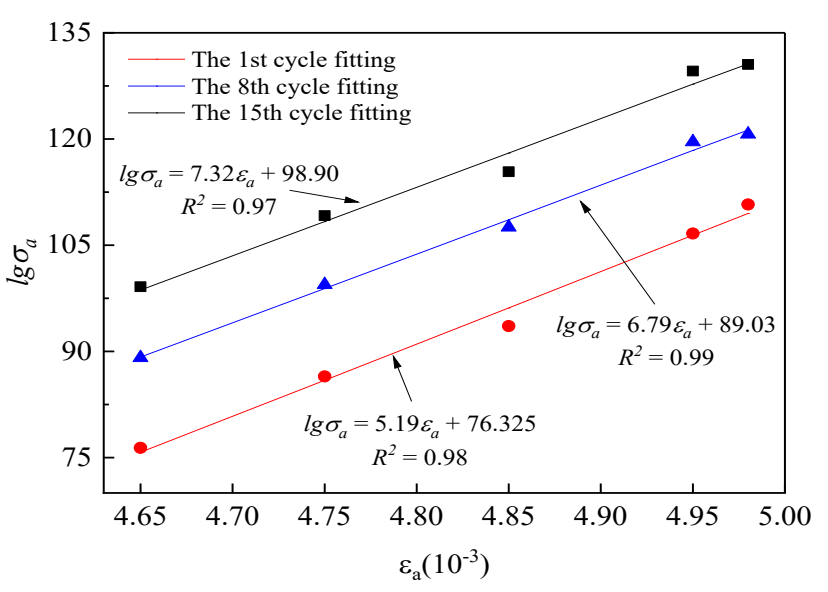

(b) $\lg \sigma_{a}-\varepsilon_{a}$

Fig. 9. Fitted Relation Graph of Cyclic Loading/Unloading-Hydraulic Coupling Tests

Following Figs. 9(a) and (b) and Eq. (10), the damage variable is calculated, and the other parameters are summarized in Table 2. On the basis of this variable, the fitted relation curves as shown in Fig. 10 are obtained, permeability shows a linear relationship with the damage variable, and the tested permeability shows a high goodness of fit with the derived damage variable. Under different confining and osmotic pressures, the rock permeability and damage variable coefficient introduced in this study are approximately 0.9 .

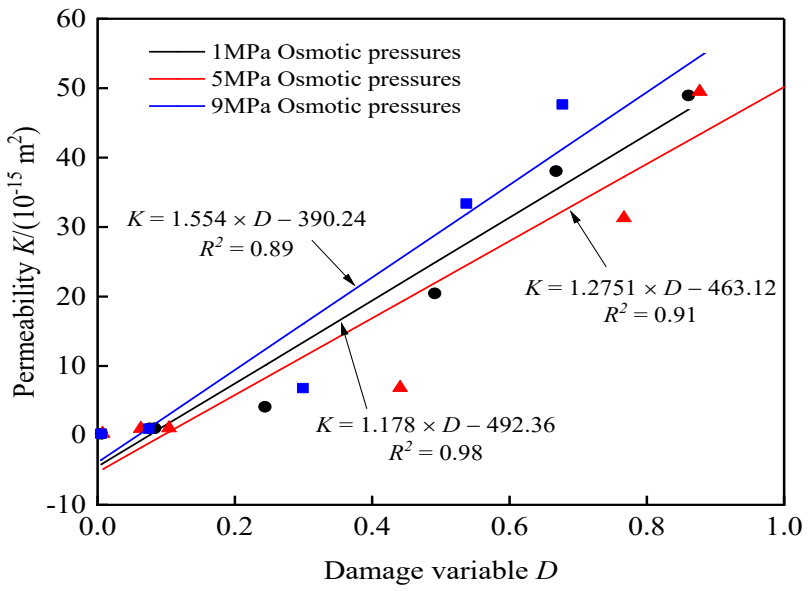

(a) $\sigma_{3}=10 \mathrm{MPa}$

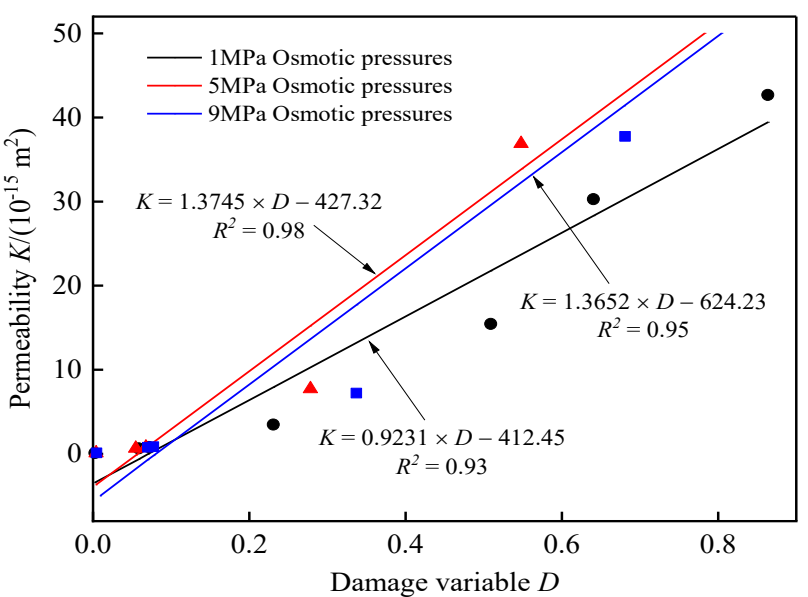

(b) $\sigma_{3}=15 \mathrm{MPa}$

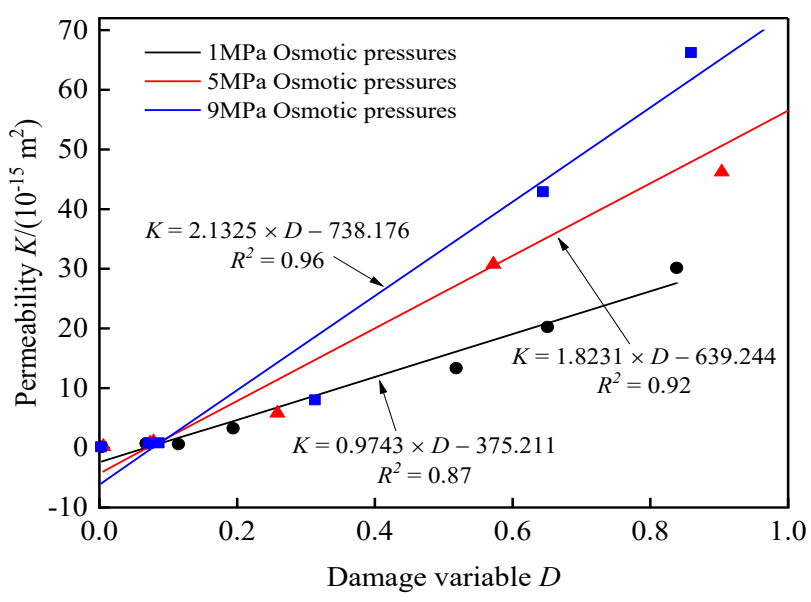

(c) $\sigma_{3}=20 \mathrm{MPa}$

Fig. 10. Fitted Relation Curve between Permeability and Damage Variable in Cyclic Loading-Hydraulic Coupling Tests under Different Confining Pressures

Table 2. Calculated Damage Variable and Other Parameters

\begin{tabular}{l|l|l|l|l|l|l|l}
\hline Parameters & Initial & Pressurization & Crack & Expansion & Peak value & Post-peak \\
\hline$U$ & 4.21 & 0.32 & 1.63 & 3.23 & 3.21 & 9.23 \\
$h$ & 4.76 & 5.19 & 6.79 & 7.32 & 7.92 & 10.32 \\
$D$ & 0.37 & 0.02 & 0.63 & 1.07 & 2.85 & 3.58 \\
\hline
\end{tabular}

Following the above derivation, the formula for the cyclic disturbance damage model of rocks under cyclic loading-hydraulic coupling action is obtained. This formula is obtained in consideration of various factors, including the deformation laws after the cyclic disturbance damage, loading mode, hysteretic characteristics of permeability, and damage characteristics. On the basis of this formula, a new equation for the damage factor of rock specimens after cyclic loading-hydraulic coupling action is derived. 


\subsection{Discussion}

The results of the three test schemes show that at the same deviatoric stress, the permeability in the loading process is unequal to that in the unloading process, and in each cyclic loading and unloading process, the permeability in the loading process is smaller than that in the unloading process. Under a constant osmotic pressure, the sandstone permeability decreases along with increasing confining pressure. When the confining pressure is constant, the permeability increases along with osmotic pressure.

By comparing these three schemes, the changes in the sandstone permeability after the cyclic loading and unloading under an osmotic pressure of $10 \mathrm{MPa}$ and different confining pressures and that under a confining pressure of $20 \mathrm{MPa}$ and different osmotic pressures are consistent with those obtained under the monotonic loading condition. Moreover, the change in sandstone permeability differs from that under monotonic loading, and such difference is mainly manifested after the yield stage because before this stage, the rock is still under a relatively compact state, which prevents the cyclic loading and unloading from causing any cyclic disturbance damage to the rock specimen. Therefore, the changes in permeability under these two circumstances are identical before the yield stage. The difference appearing after the yield stage may be related to the sandstone failure mode and crack development. Overall, the sandstone permeability under cyclic loading action is greater than that under monotonic loading.

\section{Conclusions}

To explore the sandstone permeability characteristics and reveal the relationship between its mechanical response and permeability characteristics, three test schemes are designed in this study, and the sandstone permeability characteristics are analyzed based on the results of these schemes. The following conclusions are drawn:

(1) When the rock is subjected to a high osmotic pressure, the increase amplitude of peak stress under a confining pressure of $10 \mathrm{MPa}$ to $15 \mathrm{MPa}$ is obviously greater than that under a confining pressure of $15 \mathrm{MPa}$ to $20 \mathrm{MPa}$. Such difference becomes more evident as the osmotic pressure increases. When the osmotic pressure is low, the increase amplitude of peak stress under a confining pressure of $10 \mathrm{MPa}$ to $15 \mathrm{MPa}$ is equivalent to that under a confining pressure of $15 \mathrm{MPa}$ to $20 \mathrm{MPa}$.

(2) In the monotonic loading-hydraulic coupling test, the sandstone permeability curves under different confining pressures hold the line and then decrease from the peak stage to the post-peak stage. The permeability change resulting from cyclic loading and unloading differs from that observed in the monotonic loading-hydraulic coupling test. In the five cyclic loading/unloading tests, the last cyclic permeability shows a highly linear correlation with confining pressure, and the permeability growth is more intense.

(3) A formula for the cyclic disturbance damage model of rocks under cyclic loading-hydraulic coupling triaxial tests is derived. Using this model, the damage facto formula of rock specimens after cyclic loading-hydraulic coupling action is acquired in consideration of multiple factors, including deformation laws after the cyclic disturbance damage, loading mode, permeability hysteresis characteristics, and damage characteristics.

This work combines a laboratory test with a theoretical study to understand the permeability of rocks in cyclic loading-hydraulic coupling triaxial tests. The established cyclic disturbance damage variable model achieves a high goodness of fit with the tested permeability, which can provide a reference value for future studies on the permeability characteristics of sandstone reservoirs. In a future study, the influence of temperature on sandstone will be examined, and the model established in this paper will be corrected to further understand the crack initiation laws and the permeability characteristics of deep sandstone reservoirs.

\section{Acknowledgements}

This work was supported by the Natural Science Foundation of China (42077254) and the Natural Science Foundation of Fujian (2020J01280,2020J05238).

This is an Open Access article distributed under the terms of the Creative Commons Attribution License.

\section{References}

1. Scesi, L., Gattinoni, P., "Roughness control on hydraulic conductivity in fractured rocks". Hydrogeology Journal, 15(2), 2013, pp.201211.

2. Hajjar, A., Scholtès, L., Oltéan, C., Buès, M. A., "Effects of the geometry of two - dimensional fractures on their hydraulic aperture and on the validity of the local cubic law". Hydrological Processes, 32(16), 2018, pp.2510-2525.

3. Zhao, C., Xing, J. Q., Niu, J. L., Ma, C. C., "Experimental study on crack propagation of precrack rock-like specimens under hydromechanical coupling". Chinese Journal of Rock Mechanics and Engineering, 38(S1), 2019, pp.2823-2830.

4. Rezaee, R., Saeedi, A., Clennell, B., "Tight gas sands permeability estimation from mercury injection capillary pressure and nuclear magnetic resonance data". Journal of Petroleum Science and Engineering, 88-89, 2012, pp.92-99.

5. Connell, L. D., Mazumder, S., Sander, R., Camilleri, M., Pan, Z. J., Heryanto, D., "Laboratory characterisation of coal matrix shrinkage, cleat compressibility and the geomechanical properties determining reservoir permeability". Fuel, 165, 2016, pp.499-512.

6. Li, G., Tang, C. A., Li, L. C., "Advances in rock deformation and failure process under water-rock coupling". Advances in Mechanics, 42(05), 2012, pp.593-619.
7. Rutqvist, J., Stephansson, O., "The role of hydromechanical coupling in fractured rock engineering". Hydrogeology Journal, 11(1), 2003, pp. $7-40$.

8. Guo, K. L., Yang, L., Sheng, X. C., Mei, J., Xiang, L. B., Zhang, B., Yang, W. M., Song, G. X., "Fracture mechanical behavior and AE characteristics of rock-like material containing 3-D crack under hydro-mechanical coupling". Rock and Soil Mechanics, 40(11), 2019, pp.4380-4390.

9. Selvadurai, A. P. S., "Normal stress - induced permeability hysteresis of a fracture in a granite cylinder". Geofluids, 15(1-2), 2015, pp.3747.

10. Al-Yaseri, A., Zhang, Y. H., Ghasemiziarani, M., Sarmadivaleh, M., Lebedev, M., Roshan, H., Iglauer, S., "Permeability Evolution in Sandstone due to CO2 Injection". Energy \& Fuels, 31(11), 2017, pp. $12390-12398$.

11. Babadagli, T., Ren, X., Develi, K., "Effects of fractal surface roughness and lithology on single and multiphase flow in a single fracture: An experimental investigation”. International Journal of Multiphase Flow, 68, 2015, pp.40-58.

12. Niya, S. M. R., Selvadurai, A. P. S., "Correlation of joint roughness coefficient and permeability of a fracture". International Journal of Rock Mechanics and Mining Sciences, 113, 2019, pp.150-162. 
13. Peng, J., Han, H. D., Xia, Q. S., Li, B., "Fractal characterization and genetic mechanism of micro-pore structure in deeply buried tight sandstone reservoirs:a case study of Kalpintag Formation in Shuntuoguole area, Tarim Basin". Acta Petrolei Sinica, 39(07), 2018, pp.775-791.

14. Lyu, X. Z., Zhao, Z. H., Wang, X. J., Wang, W. M., "Study on the Permeability of Weakly Cemented Sandstones". Geofluids, 2019, 2019, pp.1-14.

15. Yu, J., Li, H., Chen, X., Cai, Y. Y., Wu, N., Mu, K., "Triaxial experimental study of associated permeability-deformation of sandstone under hydro-mechanical coupling". Chinese Journal of Rock Mechanics and Engineering, 32(06), 2013, pp.1203-1213.

16. Faoro, I., Vinciguerra, S., Marone, C., Elsworth, D., Schubnel, A., "Linking permeability to crack density evolution in thermally stressed rocks under cyclic loading". Geophysical Research Letters, 40(11), 2013, pp.2590-2595.

17. Fujii, T., Funatsu, T., Oikawa, Y. Sorai, M., Lei, X. L., "Evolution of Permeability during Fracturing Processes in Rocks under Conditions of Geological Storage of CO2". Materials Transactions, 56(5), 2015, pp.679-686.

18. Zhang, L. M., Jiang, S. Q., Yu, J., "Experimental Research into the Evolution of Permeability of Sandstone under Triaxial Compression". Energies, 13(19), 2020, pp.5065.

19. Civan, F., "An Alternative Parameterization of Relative Permeability and Capillary Pressure Curves". SPE Journal, 26(01), 2020, pp.172-90.

20. Sakhaee-Pour, A., Agrawal, A., "Integrating acoustic emission into percolation theory to predict permeability enhancement". Journal of Petroleum Science and Engineering, 160, 2018, pp.152-159.

21. Nie, T. Y., Pu, H., Liu, G. H., Xiao, C., Ni, H. Y., "Research on splitting failure model of fractured rock mass under the coupling effect of seepage-stress". Journal of Mining \& Safety Engineering, 32(06), 2015, pp.1026-1030.

22. Li, T., Li, Q., Hu, Y., Peng, X., Feng, X., Zhu, Z. M., Zhao, Z. H., "Quantitative characterization of irregular micro-fracture network and its effect on the permeability of porous media". Petroleum Exploration and Development, 48(02), 2021, pp.368-378.

23. Sato, M., Panaghi, K., Takada, N., Takeda, M., "Effect of Bedding Planes on the Permeability and Diffusivity Anisotropies of Berea Sandstone". Springer Netherlands, 127(3), 2019, pp.587-603.

24. Yu, J., Yao, W., Duan, K., Liu, X. Y., Zhu, Y. L., "Experimental study and discrete element method modeling of compression and permeability behaviors of weakly anisotropic sandstones". International Journal of Rock Mechanics and Mining Sciences, 134, 2020, pp.104437.
25. Mcbeck, J., Mair, K., Renard, F., "How Porosity Controls Macroscopic Failure via Propagating Fractures and Percolating Force Chains in Porous Granular Rocks". Journal of Geophysical Research: Solid Earth, 124(9), 2019, pp.9920-9939.

26. Lin, C., Yu, J., Chen, X., Cai, Y. Y., Wen, Z. J., "Mesoscopic Numerical Simulation on Crack Expansion and Energy Evolution of Sandstone With Prefabricated Joint Under Hydro-Mechanical Coupling Condition". Journal of Huaqiao University(Natural Science), 39(04), 2018, pp.538-544.

27. Barroso, J. S., Murad, M. A., Pereira, P. A., "A new two-scale computational model for hydromechanical coupling in jointed rocks". Computers and Mathematics with Applications, 91, 2021,pp.67-98.

28. Wang, J. J., Chen, L., Kang, Q. J., Rahman, S. S., "The lattice Boltzmann method for isothermal micro-gaseous flow and its application in shale gas flow: A review". International Journal of Heat and Mass Transfer, 95, 2016, pp.94-108.

29. Khabbazi, A. E., Hinebaugh, J., Bazylak, A., "Determining the impact of rectangular grain aspect ratio on tortuosity - porosity correlations of two-dimensional stochastically generated porous media”. Science Bulletin, 61(08), 2016, pp.601-611.

30. Fu, X., Xie, Q., Liang, L., "Comparison of the Kaiser effect in marble under tensile stresses between the Brazilian and bending tests". Bulletin of Engineering Geology and the Environment, 74(2), 2015, pp.35-543.

31. Li, S. C., "Deformation and Damage Law and its Nonlinear Characteristics of Rock under Cyclic Load". Doctoral Dissertation of Chongqing University, China, 2008.

32. Morrow, J. D., "Internal Friction, Damping and Cyclic Plasticity". ASTM STP 378, 1965, pp.45-87.

33. Gao, Z. T., "Fatigue performance test design and data processing". Beihang University Press, 1999.

34. Mi, Z. X., Wang, F. G., Shi, N., Yu, J. Z., Sun, Z. J., "Experimental study on effect of multi-stage stress variations on permeability and pore structure of sandstone". Chinese Journal of Geotechnical Engineering, 40(05), 2018, pp.864-871.

35. Xu, J., Lu, L. F., Yang, H. W., Wang, J. N., Zhang, Y., "Experimental Research on Relationship of Load and Displacement of Universal Testing Machine". Advanced Materials Research, 1270, 2011, pp.1582-1587. 